\title{
Peningkatan Kinerja Jaringan Komputer dengan Border Gateway Protocol (BGP) dan Dynamic Routing (Studi Kasus PT Estiko Ramanda)
}

\author{
Tati Ernawati*, Jemi Endrawan \\ Program Studi Teknik Informatika \\ Politeknik TEDC Bandung \\ Cimahi \\ *tatiernawati@yahoo.com
}

\begin{abstract}
Abstrak-Routing dalam jaringan menjadi elemen utama karena merupakan proses pemilihan salah satu dari beberapa kemungkinan jalur pengiriman paket data dari alamat pengirim ke alamat tujuan. Protokol routing diperlukan untuk membentuk tabel routing berdasarkan informasi routing yang dipertukarkan setiap selang waktu tertentu sehingga pengalamatan pada paket data yang akan dikirim menjadi lebih jelas. Penelitian ini membangun dan mengkaji kinerja jaringan komputer (computer network performance) pada studi kasus di perusahaan yang bergerak di bidang jasa layanan internet, peningkatan kebutuhan jasa layanan internet menuntut adanya pengelolaan jaringan internal di perusahaan dalam upaya peningkatan kinerja jaringan komputer. Metode comparison testing digunakan dalam pengujian, parameter yang diuji adalah latency dan traceroute menggunakan dynamic routing Border Gateway Protocol (BGP). Hasil uji menunjukkan sistem jaringan komputer dengan BGP memiliki efisiensi jaringan yang tinggi dengan rata-rata latency $0 \mathrm{~ms}$ ( $82 \mathrm{~ms}$ tanpa BGP) dan traceroute (konten lokal) 4 hop (8 hop tanpa BGP), namun traceroute (konten non lokal) memiliki nilai persentase yang sama dikarenakan seluruh prefix non lokal harus diperoleh dari port backbone (port lama tanpa BGP).
\end{abstract}

Kata Kunci: kinerja jaringan komputer, dynamic routing, Border Gateway Protocol, latency, traceroute

\section{Pendahuluan}

Koneksi antar jaringan (internet) terbentuk dari jaringan yang berbeda-beda. Supaya antar jaringan tersebut dapat saling berkomunikasi maka diperlukan teknik tertentu. Jaringan luas (Wide Area Network = WAN) menggunakan teknologi Transmission Control Protocol/ Internet Protocol (TCP/IP) menggunakan nomor sebagai kode lokasi sehingga pengiriman paket data dapat sampai ke alamat yang dituju. TCP/IP membagi tugas masingmasing perangkat transmisi yaitu penerimaan paket data dan pengiriman paket data dalam jaringan sehingga jika terjadi permasalahan dalam pengiriman paket data dapat dipecahkan dengan baik [1].

Routing pada jaringan menjadi teknik penting dalam transmisi data karena routing merupakan proses pemilihan salah satu dari beberapa kemungkinan jalur pengiriman paket data dari alamat pengirim ke alamat penerima/ tujuan. Peta atau tabel routing digunakan router untuk mengetahui bagaimana meneruskan paket-paket ke alamat tujuan dengan menggunakan jalur terbaik [2]. Protokol routing diperlukan untuk membentuk tabel routing berdasarkan informasi routing yang dipertukarkan setiap selang waktu tertentu sehingga pengalamatan pada paket data yang akan dikirim menjadi lebih jelas. Penggunaan teknik routing pada jaringan berskala besar seperti dynamic routing mengindikasikan bahwa terdapat dinamika dalam suatu jaringan. Jaringan komputer dapat mengalami gangguan pada router seperti terputusnya koneksi yang berakibat router lain harus melakukan update pada tabel routing.

Terdapat beberapa penelitian yang telah dilakukan dengan topik yang sama tekait routing protokol BGP. Nabella dalam [3] mengkaji penerapan BGP dalam jaringan baik pada sistem otonom (Autonomous System $=$ AS) yang sama maupun berbeda dengan atribut dalam pemilihan jalur pada jaringan yaitu weight dan local preference. I Gede Putra, dkk dalam [4] mendesain jaringan dengan tools Graphical Network Simulator menggunakan protokol Internal Border Gadeway Protokol (iBGP) yang difokuskan pada analisis kebijakan dalam memanipulasi informasi routing mencakup multipath, confederation, router reflector, next hop dan route map. Caesar, dkk dalam [5] memaparkan tentang policy routing protokol BGP pada jaringan ISP, sementara itu Huston [6] menganalisis sistem tabel routing BGP pada internet. 


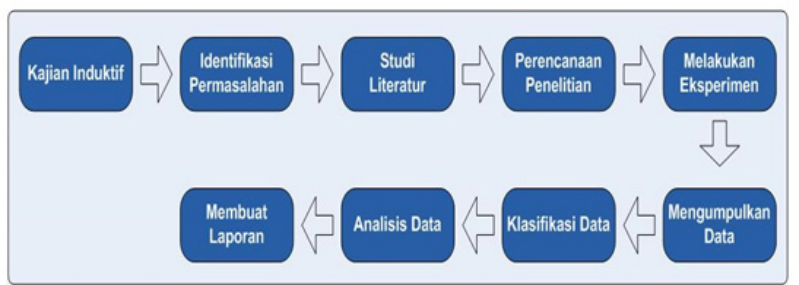

Gambar 1. Metode ekperimen [7]

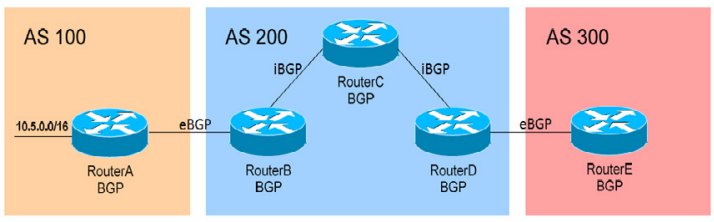

Gambar 2. eBGP dan iBGP [9]

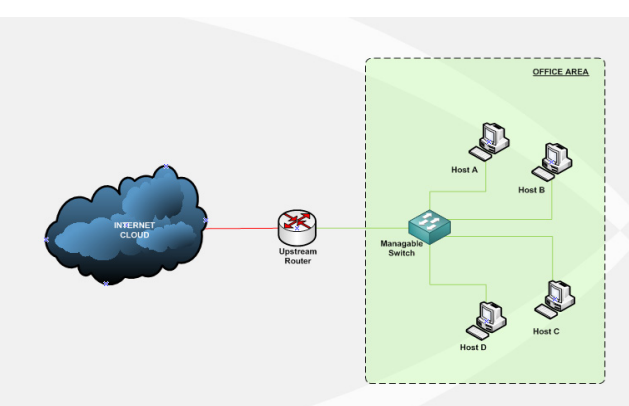

Gambar 3. Topologi Jaringan PT Estiko Ramanda yang berjalan

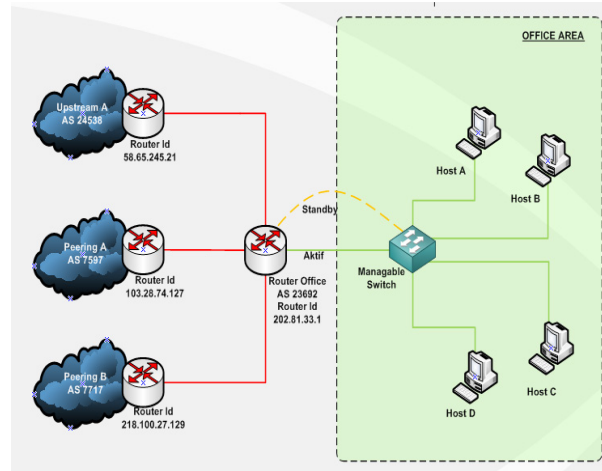

Gambar 4. Rancangan topologi Jaringan PT Estiko Ramanda dengan dynamic routing BGP

Namun, penulis belum menemukan penelitian yang mengambil parameter latency dan traeroute untuk mengamati kinerja jaringan komputer yang dibangun. Penulis mengambil studi kasus pada perusahaan yang bergerak di bidang jaringan internet (ISP) yaitu PT Estiko Ramanda berlokasi di Jakarta. Permasalahan yang dihadapi perusahaan yaitu kebutuhan konsumen akan jasa layanan internet semakin meningkat. Peningkatan kebutuhan tersebut menuntut adanya pengelolaan jaringan internal di perusahaan, dalam upaya peningkatan kinerja jaringan komputer (computer network performance). Berdasarkan permasalahan tersebut penulis melakukan kajian menggunakan metode dynamic routing BGP yang difokuskan kepada peningkatan kinerja jaringan yaitu latency dan traceroute yang dibandingkan dengan sistem yang sedang berjalan. BGP digunakan karena menjadi sebuah protokol routing yang dipandang mampu menjamin performance routing antar jaringan yang berbeda AS, memiliki sifat scalability dan konvergensi yang mampu bekerja dengan baik dalam sebuah AS maupun antar AS.

Paper ini selanjutnya ditulis sebagai berikut. Bagian 2 menjelaskan metode dan berisi uraian tentang langkahlangkah dalam penelitian yang dilakukan. Bagian 3 menyajikan hasil penelitian berupa proses rancang bangun jaringan komputer menggunakan dynamic routing BGP. Bagian 4 memaparkan analisis dan diskusi berupa hasil pengujian terhadap kinerja jaringan yang difokuskan pada parameter latency dan traceroute serta perbandingan hasil penelitian penulis dengan hasil penelitian sebelumnya. Bagian 5 memberikan kesimpulan berdasarkan hasil kajian dan hasil uji.

\section{Metode}

Metodologi penelitian yang digunakan adalah metode eksperimen [7] yang terdiri dari 9 (sembilan) tahapan seperti gambar 1 .

\section{a. Kajian Induktif}

Kajian induktif bertolak dari kaidah (hal-hal atau peristiwa) khusus untuk menemukan kaidah yang umum, berfokus kepada sebagian kecil dari fenomena yang relevan dengan permasalahan yang diamati. Kajian induktif dilakukan dengan mengkaji tentang BGP secara khusus yang merupakan bagian dari berbagai jenis dynamic routing secara umum.

\section{b. Studi Literatur}

Pada bagian ini akan dipaparkan beberapa konsep dasar terkait penelitian yang dikaji.

1) Broadway Gateway Protocol (BGP)

BGP adalah protokol routing standar yang bertujuan untuk memilih jalur-jalur interdomain. Fungsi utama dari BGP untuk mempertukarkan network reachability information antar suatu BGP router dengan BGP router yang lain. BGP tidak dibangun untuk rute dalam satu AS, tetapi dibangun untuk rute antar AS [8]. Informasi tersebut mencakup informasi jumlah AS yang berada dalam jalur penyampaian informasi. Terdapatnya informasi ini, dapat dibentuk grafik dari AS path yang saling terkoneksi sehingga dapat menghindari terjadinya routing loop. Selain fungsi di atas, BGP juga digunakan untuk menerapkan policy routing di tingkat interdomain.

2) Operasi BGP

Informasi routing dipertukarkan dengan membangun sebuah sesi yang berlandaskan pada koneksi TCP antar satu BGP router dengan BGP router yang lain [9]. Terdapat dua jenis hubungan BGP yaitu iBGP (internal BGP) yang berfungsi agar router-router internal mengetahui rute untuk mencapai suatu tujuan dan eBGP (external BGP) yang berfungsi untuk mengumumkan reachable prefixes ke BGP router tetangga [10]. Perbedaan iBGP dengan eBGP adalah bahwa iBGP tidak melakukan perubahan atribut AS path. Untuk menghindari routing loops, dalam satu AS koneksi antar BGP router dengan iBGP diterapkan topologi full mesh. Gambar 2 menunjukkan 
contoh sesi iBGP dan eBGP.

Setelah semua route yang terbaik diumumkan ke BGP router tetangga, BGP router kemudian menangani kestabilan tabel routing yang dimilikinya. Apabila ada perubahan tabel routing, hanya informasi update yang diumumkan ke BGP peer-nya. BGP tidak mensyaratkan refresh tabel routing secara periodik oleh karena itu agar perubahan policy lokal dapat langsung diterapkan dengan benar tanpa perlu mereset sesi BGP, diperlukan kemampuan route refresh dari router BGP tersebut [10].

3) Pemilihan Rute dalam BGP

Terdapat 4 (empat) komponen utama dalam memahami proses pemilihan rute dalam BGP. Komponen pertama adalah filter input dan output yang dapat dikonfigurasikan untuk setiap sesi BGP. Fungsi dari filter rute router atau dapat juga digunakan untuk memanipulasi atribut rute adalah untuk menolak rute yang diterima atau dikirim oleh tersebut. Proses filter ini dilakukan oleh operator jaringan. Komponen kedua adalah tabel routing BGP, tabel routing ini berisi semua rute yang diterima oleh router dan lolos dari proses filter input. Atribut dari route disimpan dalam tabel routing dan dilakukan proses update oleh filter input. Komponen ketiga adalah decision process, terjadi pemilihan rute terbaik dari ruterute yang disimpan dalam tabel routing untuk setiap prefix tujuan. Apabila sebuah rute dipilih sebagai rute terbaik untuk suatu prefix tujuan, maka rute tersebut diinstal di tabel forwarding dan diumumkan ke router tetangga. Tabel forwarding merupakan komponen keempat dari router. Setiap paket yang diterima, tabel forwarding akan dilihat kemudian ditentukan outgoing interface yang digunakan untuk meneruskan paket ke tujuan.

4) Latency dan Traceroute

Latency dalam jaringan komputer didefinisikan sebagai banyaknya waktu yang dibutuhkan satu paket data untuk kembali ke pengirimnya dari satu titik ke titik yang lain. Latency bergantung pada kecepatan media transmisi dan penundaan transmisi oleh perangkat (misal router dan modem). Latency rendah mengindikasikan efisiensi jaringan yang tinggi [11].

Traceroute (Tracert) adalah perintah untuk menunjukkan rute yang dilewati paket untuk mencapai tujuan. Dilakukan dengan mengirim pesan Internet Control Message Protocol (ICMP) Echo Request ke tujuan dengan nilai Time to Live yang semakin meningkat. Rute yang ditampilkan adalah daftar interface router (yang paling dekat dengan host) yang terdapat pada jalur antara host dan tujuan [12].

\section{c. Perencanaan Penelitian}

Tahap ini ditentukan objek penelitian beserta pembuatan instrumen penelitian yang diperlukan. Objek penelitian ini mengambil studi kasus di PT Estiko Ramand, perusahaan yang bergerak di bidang penyediaan jasa internet (provider) yang beralokasi di Jakarta. Instrumen penelitian dibuat untuk memperoleh data di lapangan yang dipergunakan untuk membangun dan menguji kinerja jaringan.

\section{d. Eksperimen}

Pelaksanaan eksperimen dilakukan untuk membangun sistem, menguji kebenaran cara kerja dan mengukur kinerja sistem jaringan yang difokuskan pada parameter latency dan traceroute.

\section{e. Pengumpulan Data, Klasifikasi Data dan Analisis Data}

Data diperoleh dari hasil eksperimen berupa data hasil uji kinerja jaringan. Berdasarkan hasil ekperimen data diklasifikasikan menjadi data kinerja jaringan yang sedang berjalan dan data kinerja jaringan yang dibangun (menggunakan protokol BGP) kemudian dilakukan analisis data. Analisis data dilakukan dengan komparasi kinerja jaringan hasil eksperimen sebelum dan sesudah implementasi BGP berdasarkan hasil uji, adapun data yang dianalisis mencakup parameter latency dan traceroute.

\section{f. Identifikasi Permasalahan}

Berdasarkan kajian induktif diidentifikasi permasalahan yang dikaji yaitu bagaimana membangun jaringan komputer dengan menggunakan protokol BGP dan bagaimana hasil uji jika dibandingkan dengan sistem jaringan yang sedang berjalan (eksisting).

\section{HASIL}

Hasil yang dicapai oleh peneliti adalah sistem jaringan komputer menggunakan dynamic routing BGP.

\section{a. Tahap Perancangan Topologi Jaringan}

Topologi jaringan ini berupa gambar router-router beserta konektivitas layer 3 antar router-router tersebut. Topologi yang digunakan berdasarkan pada topologi jaringan ISP yang dilengkapi AS Number. Topologi yang merepresentasikan kondisi jaringan PT Estiko Ramanda, pemodelan topologi hanya dilakukan pada beberapa router yang menjadi ASBR (Autonomous System Border Router) dan router yang mengendalikan pemilihan rute. Hasil dari pemetaan topologi jaringan PT Estiko Ramanda dapat dilihat pada gambar 3 .

Pada gambar 4 topologi yang sekarang berjalan akan ditambahkan router yang berfungsi sebagai router border sekaligus router distribusi yang terkoneksi langsung dengan managable switch.

\section{b. Tahap Identifikasi Kebutuhan Perangkat Jaringan}

Perangkat jaringan menggunakan 1 unit Router, 1 unit managable switch dengan IP Public dan Autonomous System Number (AS Number). Router digunakan sebagai router border atau perangkat yang berhubungan langsung dengan router upstream atau router lawan sedangkan fungsi managable switch adalah sebagai perpanjangan tangan dari fungsi router sebagai perangkat distribusi ke arah end user. Managable switch digunakan karena perangkat tersebut dapat memisahkan link di layer 2 dengan penggunaan Virtual LAN (VLAN). Spesifikasi router seperti pada tabel 1 . 
Tabel 1. Spesifikasi Perangkat Jaringan

\begin{tabular}{|c|c|c|c|}
\hline \multirow{2}{*}{ No } & \multicolumn{3}{|r|}{ Perangkat Keras } \\
\hline & Jenis & Type & $\begin{array}{ll}\text { Spesifikasi } \\
\end{array}$ \\
\hline 1 & $\begin{array}{l}\text { Mikrotik } \\
\text { Routerboard }\end{array}$ & $\begin{array}{l}\text { CCR1016- } \\
\text { 12G }\end{array}$ & $\begin{array}{ll}\text { - } & \text { Tilera Tile-Gx16 1.2GHz 16 Cores } \\
\text { - } & \text { RAM 2GB } \\
\text { - } & \text { 12 LAN Gigabit port }\end{array}$ \\
\hline 2 & $\begin{array}{l}\text { C i s c o } \\
\text { Catalyst }\end{array}$ & $\begin{array}{l}\text { WS- } \\
\text { C3750G- } \\
\text { 24TS-S1U }\end{array}$ & $\begin{array}{ll}\text { - } & 24 \text { Ethernet } 10 / 100 / 1000 \text { ports } \\
\text { - } & \text { 4 SFP-based Gigabit } \\
\text { - } & \text { Ethernet ports }\end{array}$ \\
\hline
\end{tabular}

\begin{tabular}{|c|c|c|c|}
\hline \multirow{2}{*}{ No IP } & \multicolumn{3}{|c|}{ IP Address } \\
\hline & Subnet & Jumlab Host & Status \\
\hline 202.81.32.0 & $/ 24$ & 254 & Tidak di Advertise \\
\hline 202.81.33.0 & $/ 24$ & 254 & Tidak di Advertise \\
\hline 202.81.34.0 & $/ 24$ & 254 & Advertise ke Upstream 1 \\
\hline 202.81.35.0 & $/ 24$ & 254 & Advertise ke Upstream 1 \\
\hline 202.81 .36 .0 & $/ 24$ & 254 & Advertise ke Upstream 1 \\
\hline 202.81.37.0 & $/ 24$ & 254 & Advertise ke Upstream 1 \\
\hline 202.81.38.0 & $/ 24$ & 254 & Advertise ke Upstream 1 \\
\hline 202.81.39.0 & $/ 24$ & 254 & Advertise ke Upstream 1 \\
\hline 202.81.40.0 & $/ 24$ & 254 & Advertise ke Upstream 1 \\
\hline 202.81.41.0 & $/ 24$ & 254 & Advertise ke Upstream 1 \\
\hline 202.81.42.0 & $/ 24$ & 254 & Advertise ke Upstream 1 \\
\hline 202.81.43.0 & $/ 24$ & 254 & Advertise ke Upstream 1 \\
\hline 202.81.44.0 & $/ 24$ & 254 & Advertise ke Upstream 1 \\
\hline 202.81.45.0 & $/ 24$ & 254 & Advertise ke Upstream 2 \\
\hline 202.81.46.0 & $/ 24$ & 254 & Advertise ke Upstream 2 \\
\hline 202.81.47.0 & $/ 24$ & 254 & Advertise ke Upstream 2 \\
\hline
\end{tabular}

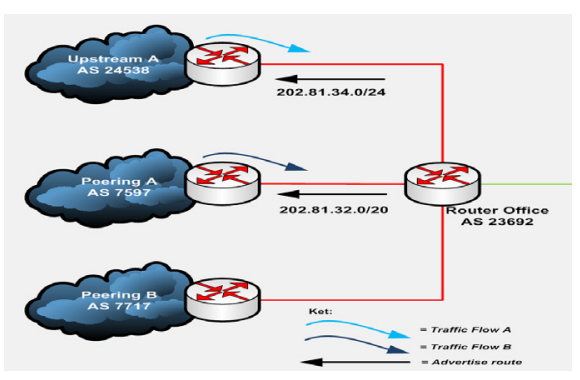

Gambar 5. Load balancing dengan selective advertisement

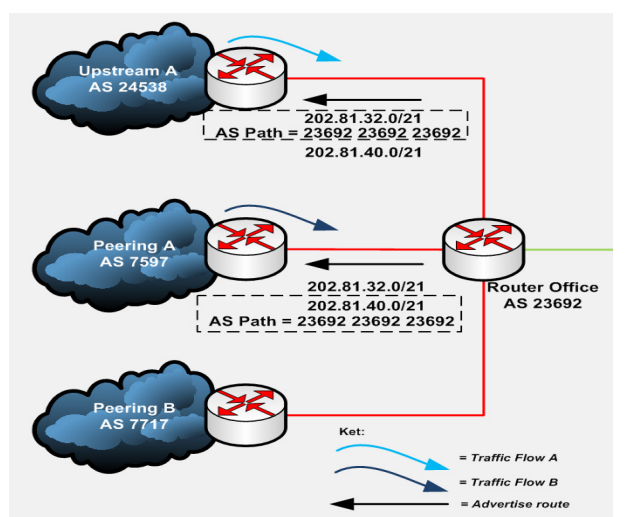

Gambar 6. Load Balancing Incoming Traffic dengan AS Path Prepending

Tabel 3. Spesifikasi Koneksi Jaringan 


\begin{tabular}{ccccl}
\hline \multirow{2}{*}{ No } & \multicolumn{4}{c}{ Koneksitivitas } \\
\cline { 2 - 5 } & Jenis & Kecepatan & Status & Keterangan \\
\hline 1 & Upstream & $140 \mathrm{Mbps}$ & Aktif & Non lokal \\
2 & IIX & $1 \mathrm{Gbps}$ & Belum Aktif & Lokal \\
\hline
\end{tabular}

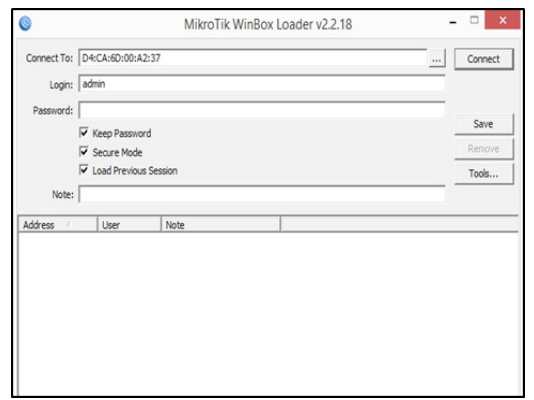

Gambar 7. Winbox Interface

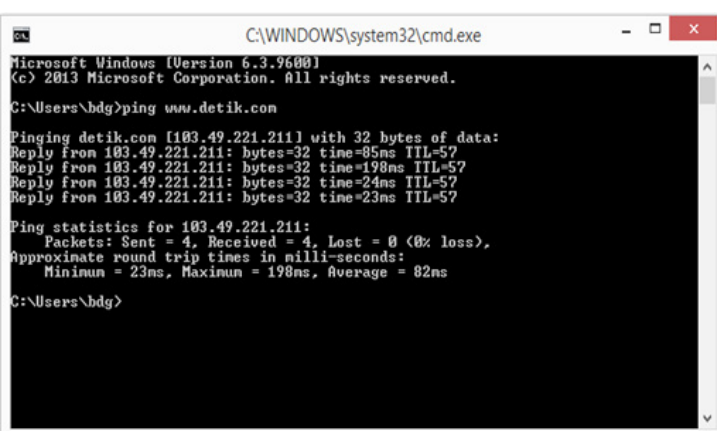

Gambar 8. Latency konten lokal sebelum BGP

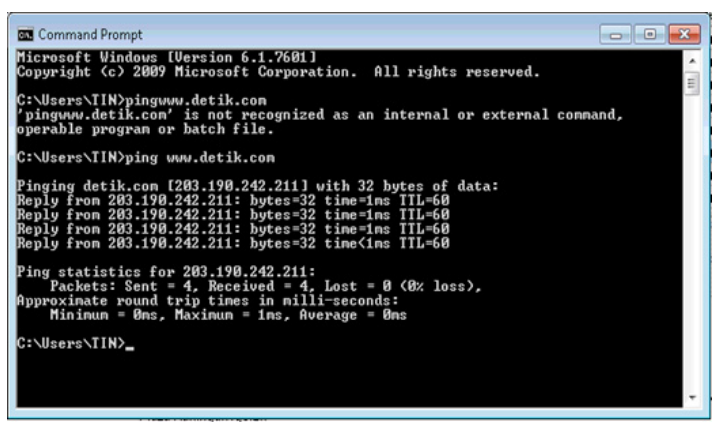

Gambar 9. Latency konten lokal sesudah BGP

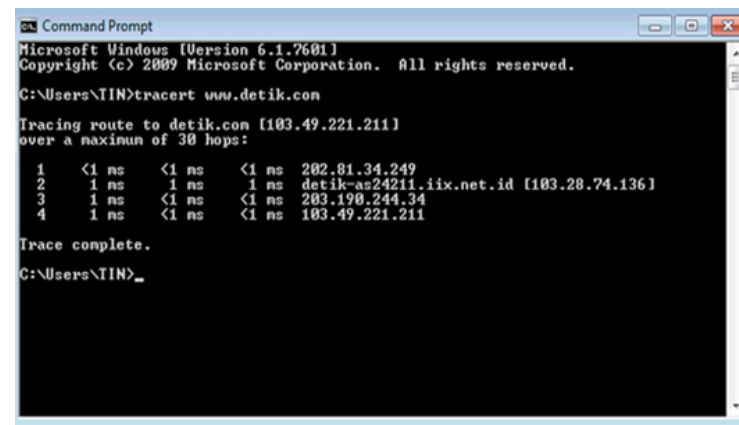

Gambar 10. Traceroute konten lokal sesudah BGP

c. Tahap Konfigurasi dan Implementasi Sistem Jaringan

IP Public dan $A S$ Number diperoleh dari Asosiasi Penyelenggara Jasa Internet Indonesia (APJII). IP Address dan spesifikasi koneksi jaringan pada Tabel 2 dan Tabel 3.

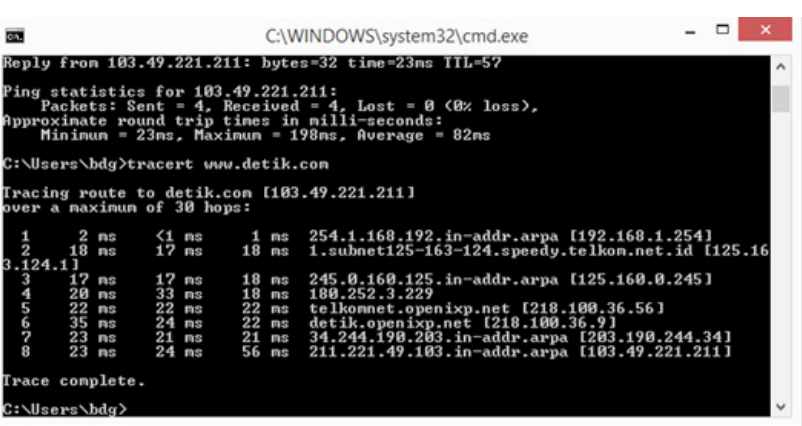

Gambar 11. Traceroute konten lokal sebelum BGP

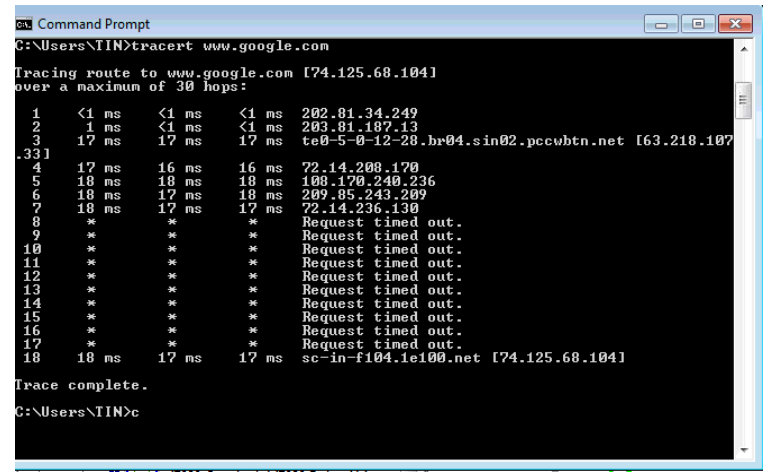

Gambar 12 Traceroute Content Non Lokal Sebelum BGP

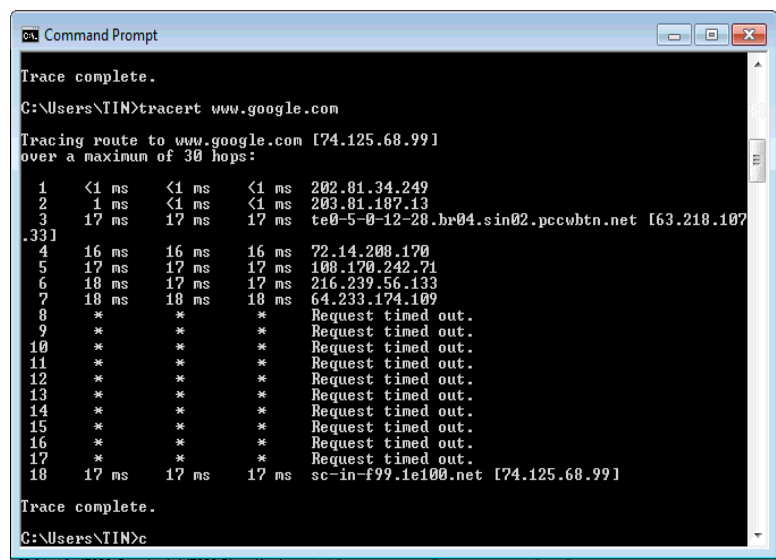

Gambar 13. Traceroute Content Non Lokal Sesudah BGP

Berdasarkan topologi jaringan yang dibuat dilakukan konfigurasi sebagai berikut:

1) Interkoneksi fisik antar perangkat.

Pemasangan interkoneksi dilakukan dengan menghubungkan interface fisik dari semua perangkat sesuai dengan gambar 3. Kabel Unshielded Twisted-Pair (UTP) digunakan dalam membangun jaringan keseluruhan interkoneksi

2) Interkoneksi virtual.

Pengalokasian IP Address Intranet dilakukan oleh administrator IP sedangkan untuk kebutuhan interdomain IP Address ditentukan dari persetujuan pihak upstream provider.

3) Konfigurasi intranet.

Konfigurasi ini dilakukan pada managable switch dengan menggunakan Virtual Local Area Network (VLAN).

4) Sesi-sesi BGP.

Pada tahapan ini akan dibangun sesi-sesi BGP antar router, pada jaringan yang akan dibuat ini 
akan dibangun 3 sesi BGP yaitu dengan pihak upstream provider, peering A dan peering $\mathrm{B}$.

5) BGP policy.

Policy diterapkan pada setiap sesi BGP antar router. Konfigurasi diperlukan dalam traffic engineering, karena pada konfigurasi ini dilakukan rekayasa routing maupun bandwidth. BGP Policy mengendalikan outgoing traffic maupun incoming traffic. Atribut Local_Pref digunakan pada pengendalian outgoing traffic yaitu dengan menentukan nilai dari Local_Pref di setiap sesi BGP. Sesi BGP dengan nilai Local_Prefyang lebih besar akan lebih dipilih dibandingkan dengan Local_Pref yang lebih kecil. Nilai default Local_Pref adalah 100.

Router Office melakukan advertise prefix 202.81.32.0/20 ke arah Peering A dan advertise prefix 202.81.34.0/24 ke arah upstream A. Tujuannya incoming raffic menuju ke prefix 202.81.34.0/24 dapat melalui jalur traffic flow A, sedangkan menuju host tujuan yang masih dalam prefix 202.81.32.0/20 dapat melalui traffic flow B sehingga dicapai kondisi loadbalance incoming raffic. Tuning BGP dapat menyebabkan kegagalan sistem apabila terjadi masalah pada jalur antara router office dengan upstream A, akibatnya seluruh host selain dalam prefix 202.81.34.0/24 tidak akan dikenali oleh internet, untuk menghindarinya prefix 202.81.32.0/20 harus dilakukan advertise juga ke arah router peering A.

Teknik lain untuk mengendalikan incoming traffic dengan As_Path prepending. Gambar 6, pembagian prefix 202.81.32.0/20 menjadi dua bagian yaitu prefix 202.81.32.0/21 dan 202.81.40.0/21. Prefix 202.81.32.0/20 dilakukan advertise ke arah router peering A tanpa AS path prepending dan prefix 202.81.40.0/21 dengan As_Path prepending sebanyak 3(tiga) kali. Sebaliknya, prefix 202.81.32.0/21 dilakukan advertise ke arah router upstream A dengan As_Path prepending 3 kali sedang prefix 202.81.40.0/21 tanpa As_Path prepending. Hal ini dilakukan untuk loadbalance trafik yang masuk ke AS 23692. Jalur traffic flow A akan menjadi jalur utama untuk trafik menuju prefix 202.81.40.0/21 dan jalur backup untuk prefix 202.81.32.0/21; berlaku sebaliknya untuk jalur traffic flow B. Interkoneksi menggunakan IIX yang merupakan produk APJII dimana semua anggota dapat melakukan share dan akses content dengan anggota lainnya sehingga mempersingkat rute yang dibutuhkan ke arah content tujuannya. Pada tahapan ini akan diaktifkan koneksi peering dengan IIX sehingga PT Estiko Ramanda mempunyai 2 kaki sebagai jalur backbone

Konfigurasi BGP jaringan menggunakan mikrotik dilakukan dengan menggunakan command line interface atau winbox.Tampilan awal winbox dapat dilihat pada gambar 7.

\section{Diskusi}

\section{a. Pengujian}

Pengujian dilakukan dengan metode comparison testing yaitu dengan mengambil data yang masuk dan keluar pada port trunk yang mengarah ke jaringan internal. Data yang masuk dan keluar dibandingkan antara data sebelum BGP diimplementasikan dan setelah BGP diimplementasikan. Parameter yang diuji mencakup latency dan traceroute.

\section{b. Hasil Pengujian}

Pengujian dengan ping test dilakukan untuk uji latency ke arah IP tujuan dan traceroute untuk memperlihatkan rute yang dilalui ke arah IP tujuan. Situasi saat BGP belum diimplementasikan pada jaringan diperlihatkan di gambar 8, yang menunjukkan latency ping ke arah konten lokal dengan nilai rata-rata sebesar 82 ms. Ketika BGP telah diimplementasikan, latency turun ke angka rata-rata sebesar 0 ms (lihat gambar 9). Sebagai konsekuensi penurunan latency, kecepatan akses ke arah konten lokal lebih cepat setelah BGP diimplementasikan pada jaringan.

Gambar 10 memperlihatkan hasil traceroute ke arah konten lokal ketika BGP sudah diimplementasikan pada jaringan. Gambar menunjukan rute ke arah konten tersebut terdapat 4 hop atau 4 router yang dilalui untuk mencapai IP tujuan

Gambar 11 memperlihatkan hasil traceroute ketika BGP belum diimplementasikan pada jaringan. Gambar memperlihatkan bahwa untuk mencapai IP tujuan, paket data harus melewati rute yang terdiri dari 8 hop atau 8 router.

Gambar capture yang telah disajikan menunjukkan bahwa setelah implementasi BGP trafik ke arah konten lokal akan berpindah melalui rute yang lebih pendek atau sedikit. Untuk akses ke konten non lokal trafik masih melewati port backbone lama karena seluruh prefiks non lokal hanya didapatkan dari port backbone lama. Gambar 12 dan gambar 13 memperlihatkan rute yang dilalui paket data ketika dilakukan akses terhadap konten non lokal. Rute yang sama ditempuh meskipun BGP sudah diimplementasikan sebab port backbone 2 atau port baru tidak mendapatkan prefiks ke arah non lokal.

\section{c. Diskusi}

Hasil pengujian yang telah disajikan menunjukkan bahwa routing BGP menghasilkan kinerja (performance) jaringan komputer lebih baik. Hasil senada diperoleh oleh beberapa peneliti lain yang mengamati kinerja routing protokol BGP.

Hasil penelitian [3] menyimpulkan bahwa BGP menjamin jaringan bebas loop. Analisis terhadap atribut weight menunjukkan terjadinya advertise ke router apabila ada perangkat yang memiliki nomor AS sama. Pada jaringan eksternal, bobot tertinggi dipilih sebagai jalur terbaik untuk mencapai tujuan, dan apabila mengalami gangguan koneksi maka jalur lain dijadikan jalur back-up. Localpreference digunakan pada router internal dengan nomor AS yang sama, bobot local-preference tertinggi menjadi jalur terbaik yang dipilih untuk mencapai alamat tujuan.

Hasil penelitian [4] membuktikan bahwa kinerja router BGP stabil. Routing mampu mencegah failure link secara lebih baik, dan terdapat skalabilitas pada pembagian beban. Sementara hasil penelitian [5] menggarisbawahi pentingnya mekanisme kebijakan routing untuk mengatasi permasalahan implementasi BGP bagi ISP. Selanjutnya penelitian [13] menunjukkan bahwa BGP bersifat scalable, artinya implementasi dapat dikembangkan dari skala kecil ke skala besar.

\section{Kesimpulan}

Berdasarkan penelitian dapat disimpulkan telah dibangun sistem jaringan komputer dengan dynamic 
routing BGP. Hasil pengujian dengan metode comparison testing menunjukkan kinerja sistem jaringan dengan menggunakan BGP lebih baik dibandingkan tanpa BGP. Perbandingan parameter rata-rata latency diperoleh nilai $0 \%$ (hampir tanpa latency) artinya kecepatan akses lebih cepat dibandingkan tanpa BGP; parameter traceroute (kontel lokal) 50\% lebih baik dibandingkan tanpa BGP, namun untuk traceroute (kontel non lokal) memiliki nilai presentase yang sama hal ini dikarenakan seluruh prefix non lokal hanya didapatkan dari port backbone lama.

\section{Daftar Pustaka}

[1] S. Iwan, "Cisco CCNA dan Jaringan Komputer," Bandung Inform. Bandung, pp. 244-248, 2010.

[2] H. Wijaya, "Belajar Sendiri Cisco Router.” Jakarta: PT Elex Media Komputindo, 2001.

[3] S. S. Kusumawardani and I. Nabella, "SIMULASI PROSES PEMILIHAN JALUR DALAM BORDER GATEWAY PROTOCOL (BGP) BERDASARKAN ATRIBUT WEIGHT DAN LOCALPREFERENCE," Universitas Gadjah Mada, 2014.

[4] A. F. Rochim, Y. Christiyono, and I. G. P. Yasa, "DESAIN DAN SIMULASI INTERNAL BORDER GATEWAY PROTOCOL (IBGP) MENGGUNAKAN GRAPHICAL NETWORK SIMULATOR (STUDI KASUS PADA JARINGAN UNIVERSITAS DIPONEGORO)," Transmisi, vol. 16, no. 1, pp. 20-25, 2014.

[5] M. Caesar and J. Rexford, "BGP routing policies in ISP networks," IEEE Netw., vol. 19, no. 6, pp. 5-11, 2005.
[6] G. Huston, "Analyzing the Internet's BGP routing table," Internet Protoc. J., vol. 4, no. 1, pp. 2-15, 2001.

[7] Sukardi, "Metodologi Penelitian Pendidikan Kompetensi dan Praktiknya." PT Bumi Aksara, 2003.

[8] R. Kuhn, K. Sriram, and D. Montgomery, "Border gateway protocol security,” NIST Spec. Publ., vol. 800 , p. $54,2007$.

[9] E. Chen, "Route Refresh Capability for BGP-4," 2000. [Online]. Available: https://tools.ietf.org/ $\mathrm{html} / \mathrm{rfc} 2918$. [Accessed: 09-Jan-2017].

[10] A. B. Ali, M. Tabassum, and K. Mathew, "A comparative study of IGP and EGP routing protocols, performance evaluation along load balancing and redundancy across different AS," in Proceedings of the International MultiConference of Engineers and Computer Scientists, 2016, vol. 2.

[11] "Latency Definition," The Linfo website, 2017. [Online]. Available: http://www.linfo.org/latency.

[12] Traceroute, 2017. [Online], Available: https:// www.rumahweb.com/journal/traceroute-tracert. htm.

[13] K. Weitz, D. Woos, E. Torlak, M. D. Ernst, A. Krishnamurthy, and Z. Tatlock, "Scalable verification of border gateway protocol configurations with an SMT solver," ACM SIGPLAN Not., vol. 51, no. 10, pp. 765-780, 2016. 